\title{
PAINÉIS DE MADEIRA AGLOMERADA PRODUZIDOS COM SERRAGEM E POLIESTIRENO EXPANDIDO
}

\author{
Jane Eliza de Almeida ${ }^{1}$, Norman Barros Logsdon ${ }^{2}$, José Manoel Henriques de Jesus ${ }^{3}$ \\ ${ }^{1}$ Arquiteta e Urbanista, Mestranda em Engenharia de Edificações e Ambiental, UFMT, Cuiabá, MT, Brasil - jane.almeida.arq@uol.com.br \\ ${ }^{2}$ Eng. Civil, Dr., Depto. de Engenharia Florestal, Cuiabá, MT, Brasil - logsdon@ @erra.com.br \\ ${ }^{3}$ Eng. Civil, Dr., UFMT, Depto. de Engenharia Civil, Cuiabá, MT, Brasil - jmhenriques@ terra.com.br \\ Recebido para publicação: 27/01/2011 - Aceito para publicação: 31/08/2011
}

\begin{abstract}
Resumo
O presente trabalho objetiva propor um novo painel, utilizando resíduos de madeira (partículas) e plástico (adesivo). Por métodos experimentais, foram avaliados os plásticos PET (polietileno tereftalato), PEBD (polietileno de baixa densidade) e EPS (poliestireno expandido). Como material proposto, o EPS, também conhecido como isopor, foi o que forneceu os melhores resultados. Assim, foram modelados painéis com várias proporções de serragem/EPS, dissolvidos com gasolina e com gasolina e água, sendo elas 90/10, 80/20, 70/30, 60/40 e 50/50. O painel que forneceu os melhores resultados foi o de 50\% de serragem e 50\% de EPS, dissolvido em $2000 \mathrm{ml}$ de gasolina com adição de $250 \mathrm{ml}$ de água. Dos resultados de caracterização física, pode-se concluir que esses painéis são compatíveis com os padrões exigidos pelas normas brasileiras e, devido aos baixos valores de inchamento, adequados à utilização em ambientes externos. Dos resultados de caracterização mecânica, o painel apresentou bons resultados quanto à ligação interna, indicando ser promissor o uso de EPS como adesivo; entretanto, os resultados de flexão estática e tração paralela às faces foram baixos, provavelmente pelas propriedades do adesivo utilizado para o produto final.

Palavras-chave: Aglomerados; adesivos; manufatura.
\end{abstract}

\begin{abstract}
Wood panels produced with sawdust and expanded polystyrene. This work aims to propose a new particleboard, using wood sediments (particles) and plastics (adhesives). By experimental methods, the following plastics were evaluated: PET (poliethylene terephthalate), PELD (polyethylene of low density), and EPS (expanded polystyrene). As material proposed, EPS obtained the best results; panels were modeled with several proportions of Sawdust/ EPS, dissolved in gasoline and in gasoline and water, as follows: 90/10,80/20,70/30,60/40 and 50/50. The panel that presented the best results was the one constituted of 50\% EPS and 50\% sawdust, dissolved in $2000 \mathrm{ml}$ of gasoline with addition of $250 \mathrm{ml}$ of water. By the results of physical characterization it can be concluded that those panels are compatible with the patterns demanded by Brazilian Codes and, due to the low values of swelling, suitable for outdoor use. By the results of mechanical characterization, these panels presented good performance in relation to internal connection, indicating EPS use as adhesive; however, results of static bending and parallel tension to the faces were low, probably because the properties of the adhesive used on the final product.
\end{abstract}

Keywords: Particleboard; adhesives; manufacture.

\section{INTRODUÇÃO}

As questões ambientais, hoje percebidas pela humanidade, instigam a busca de novas alternativas para a melhoria mundial. Um dos setores que necessita de cuidados é o da construção civil, que gera resíduo e muitas vezes não apresenta soluções para suas consequências. Nesse caso se enquadram os sistemas construtivos e os materiais de construção, como a madeira, que também é utilizada e muitas vezes não tem o seu descarte planejado.

Do mesmo modo que as áreas de florestas plantadas estão sendo utilizadas como locais alternativos para minimização das dificuldades ambientais, também surgem no mercado novos materiais, como forma de amenizar os problemas atuais. Nesses casos se encaixam os painéis que se aproveitam de resíduos do 
beneficiamento das madeiras para sua produção. Tais materiais propostos e já consolidados no mercado também têm gerado preocupações, pois, apesar de haver muita oferta, sua procura vem aumentando a cada ano, estando muito próxima sua relação produção/consumo. Esses materiais apresentam certas restrições para a fabricação, o que implica a necessidade de pesquisa para aproveitar seus benefícios.

Para a produção de painéis aglomerados, são necessários dois materiais básicos: as partículas de madeira e os adesivos. O primeiro pode ser utilizado de variadas maneiras, quase não apresentando dificuldades, entretanto os adesivos são os produtos que apresentam alguns empecilhos, como, por exemplo, o alto custo, uma vez que chegam a representar de $35 \%$ a $60 \%$ do valor final (IWAKIRI, 2005), além de apresentarem alto teor de toxicidade (DIAS, 2005).

Alguns resíduos que precisam ser descartados podem ser reaproveitados de maneira consciente e sustentável, na construção civil, na produção de adesivos para novos painéis. Nesse caso se encaixam os plásticos de Poliestireno Expandido (EPS), conhecidos como isopor. Apesar de ser um material totalmente reciclável e reaproveitável, tem-se tornado um problema na composição dos lixos urbanos, devido ao seu grande volume (ABRAPEX, 2010).

Atualmente, a utilização abundante do isopor pode ser encontrada desde a agricultura até a construção civil. Praticamente todas as indústrias de embalagens o utilizam como forma de proteção para eletrônicos, armazenamento de alimentos, bebidas e produtos fármacos, e na área de decoração. Quanto à durabilidade, ainda não existem dados, mas, se utilizado de maneira correta, apresenta desempenho adequado ao longo de sua vida útil (ACEPE, 2010).

Os painéis de madeira aglomerada surgiram na Alemanha na década de 40, em decorrência do isolamento resultante da $2^{\mathrm{a}}$ Guerra Mundial. Como havia a dificuldade para a produção de lâminas de boa qualidade para a fabricação de compensados, restaram apenas resíduos de madeiras (DONATI, 2010). No Brasil, em 1966, as chapas de madeira aglomerada começaram a ser produzidas pela indústria iniciada pelo grupo francês Louis Dreiffus, que criou a empresa Placas do Paraná, em Curitiba, devido à abundância de resíduos produzidos na região Sul, pela indústria moveleira local (MATTOS et al., 2008). Seu emprego é muito difundido na construção civil, mas sua maior produção está voltada para a indústria moveleira.

Dada a vasta utilização da produção vigente, a necessidade de expansão na área de painéis de madeira é apropriada. Baseando-se na existência de novos materiais construtivos, nota-se que os painéis de madeira aglomerada podem ser utilizados com novos produtos, tanto partículas quanto adesivos, a partir de materiais que podem ser descartados em serrarias e lixos urbanos.

Dessa forma, o presente estudo pretende contribuir para a produção e análise de novos materiais que colaboram com a melhoria ambiental. Assim, há necessidade de se conhecer parâmetros e proporções de uso da porcentagem serragem/isopor para sua correta utilização, em larga escala, também na construção civil.

Pretende também contribuir para um maior reaproveitamento do isopor descartado pelas indústrias e no uso em geral, diminuindo a questão de resíduos plásticos que são considerados um problema devido ao grande volume, bem como com a redução do emprego de materiais naturais, uma vez que as partículas de madeira a serem utilizadas podem ser encontradas em abundância em serrarias, onde, muitas vezes, é difícil o armazenamento, auxiliando também na preservação da natureza.

Partindo-se da hipótese de que os plásticos podem ser usados como adesivo na produção de painéis de madeira aglomerada, este trabalho tem por objetivo propor um novo material alternativo utilizando-se resíduos de madeira (serragem) e aparas de isopor EPS.

\section{MATERIAIS E MÉTODOS}

\section{Materiais}

As partículas de madeiras foram extraídas de resíduo proveniente de cortes ou acabamentos em madeiras maciças da empresa Madeireira Verdão, município de Cuiabá (MT). A serragem empregada foi a das espécies peroba e cedrinho, misturadas aleatoriamente e de tamanhos não selecionados.

A fim de escolher o adesivo a ser utilizado, foram feitos estudos experimentais iniciais com alguns plásticos: PET (polietileno tereftalato), PEBD (polietileno de baixa densidade) e EPS (poliestireno expandido). A escolha partiu da premissa de que esses materiais são encontrados em abundância nos lixos urbanos e, assim, seu custo torna-se praticamente nulo se utilizados como resíduos. 
Para a dosagem dos materiais, utilizou-se uma balança com capacidade de $1500 \mathrm{~g}$ e sensibilidade de 0,2 g. Para a aplicação da pressão na montagem dos painéis, utilizou-se uma prensa, acionada por um pistão hidráulico com capacidade de 100 toneladas.

Nos ensaios de caracterização física e mecânica, foram utilizados os seguintes equipamentos:

- balança analítica de capacidade $1000 \mathrm{~g}$ e sensibilidade de $0,01 \mathrm{~g}$;

- recipiente com água destilada, com temperatura controlada de $(20 \pm 2)^{\circ} \mathrm{C}$;

- estufa de secagem e esterilização, com termômetro para temperaturas variando entre $0{ }^{\circ} \mathrm{C}$ e $360{ }^{\circ} \mathrm{C}$;

- paquímetro digital com capacidade de $15 \mathrm{~cm}$ e sensibilidade de $0,01 \mathrm{~mm}$

- máquina universal de ensaios com capacidade de $20 \mathrm{kN}$ e sensibilidade de $10 \mathrm{~N}$.

\section{Métodos}

Durante dois meses (dez./2009 a fev./2010), a serragem foi colocada em processo de secagem natural, repousando e secando ao ar. A cada 15 dias, essa serragem era misturada para que todas as partículas pudessem ser acomodadas e entrassem em contato com o ar natural. A serragem permaneceu em uma lona de polietileno, para que a umidade encontrada no piso não fosse absorvida, uma vez que a época é de muita chuva na região.

Para determinação do teor de umidade, utilizou-se o método gravimétrico, ou da pesagem, descrito na NBR 14.810, da ABNT (2006), que consta da determinação da massa inicial da amostra; colocação na estufa de secagem com temperatura de $(103 \pm 2)^{\circ} \mathrm{C}$; avaliação da massa, durante a secagem, até obter uma variação menor ou igual a $0,5 \%$ entre as 2 últimas leituras, com um período mínimo de 6 horas entre elas. Nessa situação, o material é considerado seco e avalia-se a massa seca e o teor de umidade.

Para escolher que plástico seria usado como adesivo para a confecção dos painéis, foram feitos alguns testes iniciais, utilizando-se PET, PEBD e EPS (isopor). Imaginou-se inicialmente utilizar o PET derretido pelo calor como adesivo. Como os resultados não foram positivos, houve a necessidade de novos estudos. Seguindo o intuito da melhoria ambiental, foi proposto o emprego do polímero polietileno de baixa densidade (PEBD), sacolas plásticas oriundas de supermercado, facilmente encontradas como resíduos. A utilização do PEBD como adesivo mostrou-se promissora, pois foi possível montar um painel usando múltiplas camadas de serragem intercaladas com o plástico, pressionadas a quente. Entretanto, por falta de pressão no equipamento utilizado, o painel não apresentou boa qualidade. A utilização do EPS dissolvido em gasolina como adesivo na montagem do painel mostrou-se adequada e foi utilizada neste trabalho. Dessa maneira foi escolhido o adesivo.

Quanto à manufatura dos painéis, de modo geral, a produção das chapas segue as seguintes etapas: a) obtenção dos cavacos de madeira; b) transformação dos cavacos em partículas; c) peneiramento e seleção das partículas; d) secagem das partículas até atingir a umidade desejada; e) adição da resina, do solvente, do catalisador e da emulsão de parafina, quando necessários; f) formação do colchão; g) préprensagem e prensagem; h) lixamento e aparamento das bordas (IWAKIRI, 2005).

Neste estudo, algumas alterações foram tomadas e a metodologia utilizada foi a descrita a seguir:

a) Partículas: A madeira foi obtida já em forma de serragem, de modo que foram desnecessários os processos de seleção de cavacos para a transformação em partículas. O peneiramento, propositadamente, não ocorreu, para que fosse aproveitado todo o material recebido direto da serraria. Dessa maneira, as partículas adotadas não passaram por uma pré-seleção em peneiras diferenciadas. Após a estabilização ao ar, as partículas foram analisadas quanto ao teor de umidade, para constatação do valor da umidade em que seriam utilizadas. Então foram pesadas e separadas todas as quantidades de serragem necessárias, até serem adicionadas ao adesivo.

b) Adesivo: Após ter sido selecionado o tipo de plástico a ser utilizado como adesivo, o ele foi dissolvido para que se tornasse uma goma fácil de ser misturada. $\mathrm{O}$ adesivo utilizado foi o EPS dissolvido através de solvólise com gasolina, misturado manualmente à serragem. A quantidade de adesivo foi feita por estudos e análises de ensaios físicos e mecânicos dos painéis prontos, para encontrar a melhor porcentagem. Foram utilizadas as proporções 10/90, 20/80, 30/70, 40/60 e 50/50 nos parâmetros EPS/serragem. Durante a mistura, houve adição de água para tornar o adesivo EPS, dissolvido em gasolina, mais viscoso, além de umedecer as partículas de madeira para facilitar a mistura dos materiais, diminuindo a quantidade de gasolina. A quantia utilizada de água e gasolina variou conforme a porcentagem EPS/serragem e foi encontrada experimentalmente (até obter "ponto" para misturar).

c) Pré-prensagem e prensagem: Após a mistura das partículas com o adesivo, foi formado manualmente um colchão sobre uma caixa de ferro de fundo falso e tampa removível, com dimensões de $30 \mathrm{~cm} \mathrm{x}$ 
$40 \mathrm{~cm} \times 10 \mathrm{~cm}$, produzida exclusivamente para a prensagem dos painéis. A caixa foi forrada com papel alumínio para facilitar a retirada do painel e foi feita uma pré-prensagem através da própria tampa, com peso de aproximadamente $30 \mathrm{~kg}$. Os colchões formados constituíram-se de aproximadamente $60 \mathrm{~mm}$ de altura e somente após 24 horas foram prensados e finalizados. O período de espera foi encontrado por experimentação, pois as placas confeccionadas, quando prensadas cedo demais, apresentavam defeitos, como derramamento excessivo do solvente, bolhas de ar, observadas ao retirar a tampa da caixa, colagem da massa em locais indevidos (tampa ou fundo da forma) e outros problemas que inviabilizavam sua utilização. Por último, os painéis foram submetidos à prensagem final, com carga de $480 \mathrm{kN}$, correspondente a uma pressão de $4 \mathrm{MPa}$, por um período de 12 minutos.

d) Acondicionamento: Os painéis, depois de prontos, foram acondicionados no próprio laboratório, onde ficaram secando ao ar durante três semanas, para a cura do adesivo. O tempo foi necessário para os painéis adquirirem estabilidade e poderem ser cortados, a fim de se realizar os ensaios físicos e mecânicos.

Para a melhor utilização do adesivo proposto, foram fabricadas chapas com 10\%, 20\%, 30\%, 40\% e 50\% de EPS e analisada a quantidade de adesivo necessária e suficiente para a fabricação do painel.

O peso total da placa final foi de 1500 gramas e suas porcentagens EPS/serragem se deram na proporção de 10/90, 20/80, 30/70, 40/60 e 50/50.

Em todos os painéis, a quantidade de solvente necessária para o derretimento do isopor foi de 1 vez e meia do peso total da chapa, sendo então necessários $2250 \mathrm{ml}$ de solvente. Os solventes foram testados de duas maneiras: com gasolina e água e somente gasolina.

As quantidades de materiais utilizados e o adesivo com o seu solvente são apresentados na Tabela 1.

Tabela 1. Quantidade de materiais para a manufatura dos aglomerados.

Table 1. Number of materials for manufacture of particleboard.

\begin{tabular}{lcccc}
\hline Placas & EPS $($ gramas $)$ & Serragem (gramas) & Gasolina $(\mathbf{m l})$ & Água $(\mathbf{m l})$ \\
\hline P01 & 150 & 1350 & 250 & 2000 \\
P02 & 300 & 1200 & 750 & 1500 \\
P03 & 450 & 1050 & 1250 & 1000 \\
P04 & 600 & 900 & 1500 & 750 \\
P05 & 750 & 1350 & 2000 & 250 \\
P06 & 150 & 1200 & 2250 & 0 \\
P07 & 300 & 1050 & 2250 & 0 \\
P08 & 450 & 900 & 2250 & 0 \\
P09 & 600 & 750 & 2250 & 0 \\
P10 & 750 & & & 0 \\
\hline
\end{tabular}

Para a definição da melhor relação entre EPS/serragem, foram conduzidos os ensaios previstos na Norma Brasileira NBR 14.810, da ABNT (2006), para a caracterização física das chapas (densidade, teor de umidade, absorção e inchamento) e para sua caracterização mecânica (cisalhamento, ligação interna, compressão longitudinal, tração paralela, módulo de elasticidade e módulo de ruptura na flexão estática).

Os ensaios foram realizados após a prensagem e completa cura da resina, depois de, no mínimo, 21 dias de fabricação. De cada chapa de $40 \mathrm{~cm}$ x $30 \mathrm{~cm}$, foi preparado um corpo de prova para cada um dos ensaios. Apenas para o corpo de prova de cisalhamento, que não consta em norma, foi previsto um tamanho semelhante ao previsto na NBR 7190, da ABNT (1997), embora com a espessura do painel.

Para cada característica física ou mecânica estudada, foram obtidos a média da amostra, o desvio-padrão da amostra, o coeficiente de variação da amostra e o intervalo de confiança da média.

\section{RESULTADOS E DISCUSSÃO}

\section{Estudos preliminares}

Depois de coletada a serragem, já com a umidade estabilizada após secagem ao ar, avaliou-se o teor de umidade das partículas. O resultado obtido foi de aproximadamente $11 \%$ de umidade.

Propôs-se utilizar inicialmente o PET derretido por calor como adesivo. Com o derretimento, verificou-se um ponto crítico quanto ao "gel time". Seu "tempo de panela" é muito curto, de 
aproximadamente 15 segundos, quando derretido à temperatura acima de $200{ }^{\circ} \mathrm{C}$, dificultando, desta maneira, sua manipulação. Com isso constatou-se que ocorreu um pré-endurecimento rápido, fornecendo "insuficiente mobilidade do adesivo para fluir, transferir, penetrar e umectar", requisitos indispensáveis, segundo Iwakiri (2005).

Assis (2004) afirma que "o PET, por ser um polímero de condensação, assim como os poliuretanos e as poliamidas, é mais facilmente despolimerizado por solvólise do que pela despolimerização térmica, ou catalítica", entretanto, para tal procedimento, são necessários outros produtos químicos (acetato de zinco, ácido sulfúrico, hidróxido de sódio e tolueno, entre outros), dificultando assim a execução.

Devido às dificuldades encontradas no uso de PET, foi analisada a troca do adesivo por PEBD. Derretê-lo em alta temperatura diretamente em chamas não foi possível, por isso a indicação foi a utilização com a chapa aquecida, formando colchões multicamadas intercalando a serragem com o plástico. O processo demorou aproximadamente 30 minutos e, por não haver pressão suficiente para a prensagem, o material ficou com baixa compactação. Entretanto, o adesivo comportou-se com umectação completa, havendo grande transferência do adesivo para a superfície oposta, mas não ancorada, provavelmente pelo fato de não haver pressão nem temperatura suficientes (Figura 1).

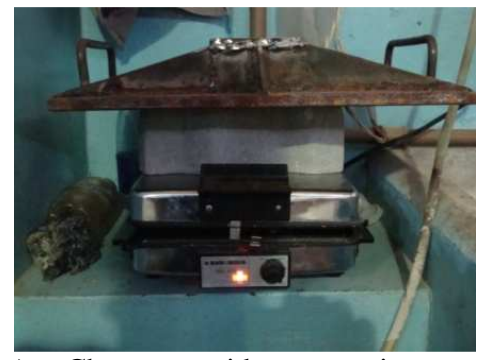

a) Chapa aquecida com a mistura

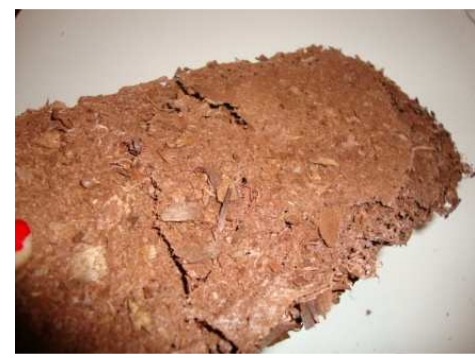

b) Painel com baixa compactação

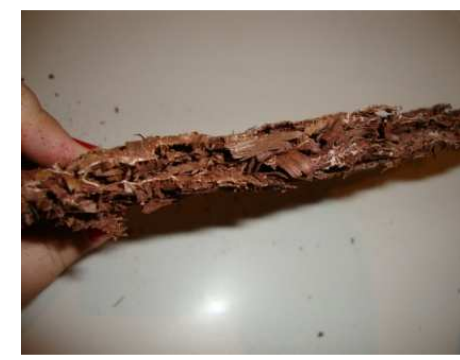

c) Resultado final

Figura 1. Resultado do teste da mistura de serragem e PEBD colocados entre chapas aquecidas.

Figure 1. Result of the test mixture of sawdust and PEBD enclosed heated plates.

Neste caso, seria necessário o uso de aparelho específico, como prensa hidráulica com controle de temperatura, para prensagem a quente que promovesse suficiente adesão.

Considerando os problemas já explicados quanto ao "gel time" do PET e a inviabilidade do PEBD, estudou-se o uso de outro adesivo que pudesse ter boa coesão, aderência e viscosidade. Optou-se pela utilização do EPS, que apresenta essas características.

Tal opção surgiu após análises de estudos com bom aproveitamento, feitos por estudantes da disciplina de Projeto Alternativo (período acadêmico de 2009) do Curso de Arquitetura e Urbanismo da Universidade do Estado do Mato Grosso (UNEMAT). Esses estudantes utilizaram o EPS dissolvido com gasolina em seus experimentos, encontrando uma boa cola (goma), que pode ser aproveitada juntamente com a serragem, pois formam uma mistura homogênea.

É interessante salientar que o derretimento do EPS acontece rapidamente a partir do momento em que há a união dos dois materiais, isopor e gasolina. Seu "gel time" é de aproximadamente 6 horas, o que possibilita um trabalho tranquilo. $\mathrm{O}$ único empecilho está no fato de, depois da união, ser necessário aguardar um tempo de cura do produto antes da prensagem, para que o EPS não perca suas características de adesivo e haja uma melhor prensagem, sem prejuízos à placa final. Após a prensagem, devem ser aguardados alguns dias ( 3 a 21, dependendo da quantidade de adesivo), para que ocorra a perda do solvente por evaporação e, em consequência, uma cura parcial.

\section{Estudo da escolha do melhor painel}

Antes de ser escolhida qual a melhor porcentagem EPS/serragem a ser utilizada para as análises finais de ensaios físicos e mecânicos, foram produzidos painéis com várias porcentagens e realizados os mesmos testes para análise de seus comportamentos. O painel com 10\% de EPS e $90 \%$ de serragem foi descartado, pois não houve união nem compactação da placa, provavelmente pela pouca quantidade de adesivo (EPS) existente. 
Os resultados de análises físicas iniciais obtidas nas diferentes porcentagens EPS/serragem encontram-se na tabela 2.

Tabela 2. Resultados das análises físicas iniciais.

Table 2. Results of initial physical analysis.

\begin{tabular}{lccccccc}
\hline $\begin{array}{l}\text { EPS/ } \\
\text { Serragem }\end{array}$ & $\begin{array}{c}\text { Solvente } \\
\text { usado }\end{array}$ & $\begin{array}{c}\text { Densidade } \\
\left(\mathbf{k g} / \mathbf{m}^{\mathbf{3}}\right)\end{array}$ & $\begin{array}{c}\text { Umidade } \\
(\mathbf{\%})\end{array}$ & $\begin{array}{c}\text { Absorção } \\
\mathbf{2 h}(\mathbf{\%})\end{array}$ & $\begin{array}{c}\text { Absorção } \\
\mathbf{2 4 h}(\mathbf{\%})\end{array}$ & $\begin{array}{c}\text { Inchamento } \\
\mathbf{2 h}(\mathbf{\%})\end{array}$ & $\begin{array}{c}\text { Inchamento } \\
\mathbf{2 4 h}(\boldsymbol{\%})\end{array}$ \\
\hline $20 / 80$ & Gasolina/água & 441,32 & 8,1 & 79,93 & 92,11 & 0,00 & 2,74 \\
$30 / 70$ & Gasolina/água & 426,74 & 8,3 & 66,81 & 82,30 & 3,09 & 0,87 \\
$40 / 60$ & Gasolina/água & 597,56 & 8,2 & 23,77 & 37,81 & 1,57 & 2,03 \\
$50 / 50$ & Gasolina/água & 646,27 & 8,2 & 8,60 & 19,25 & 0,45 & 2,14 \\
$20 / 80$ & Gasolina & 445,89 & 8,6 & 91,08 & 103,04 & 3,21 & 0,81 \\
$30 / 70$ & Gasolina & 553,98 & 9,9 & 30,87 & 79,25 & 8,40 & 16,37 \\
$40 / 60$ & Gasolina & 668,39 & 11,0 & 22,77 & 52,23 & 5,67 & 12,79 \\
$50 / 50$ & Gasolina & 643,05 & 10,1 & 12,94 & 26,92 & 1,72 & 4,63 \\
\hline
\end{tabular}

Pelos resultados dos ensaios físicos, percebe-se que os valores de densidade parecem estar relacionados à proporção de serragem existente no painel, pois, de modo geral, quanto maior o teor de serragem, maior a densidade apresentada. Apenas o painel com 50\% de EPS 50\% serragem, dissolvidos em gasolina, fugiu a essa regra. Pelos valores apresentados em norma, tanto os painéis 20/80 e 30/70, com gasolina e água, quanto o painel 20/80 em gasolina, podem ser descartados, pois não se enquadram nos padrões exigidos. As chapas brasileiras são classificadas como de média densidade, com valores que variam de $551 \mathrm{~kg} / \mathrm{m}^{3}$ a $750 \mathrm{~kg} / \mathrm{m}^{3}$ (ABNT, 2006).

Observa-se, pela análise de teor de umidade, que não há como descartar nenhum dos painéis, pois todos estão enquadrados nos padrões exigidos em norma, que é de 5\% a $11 \%$. Intui-se, comparando as análises de densidade e teor de umidade dos painéis dissolvidos em gasolina, que o comportamento da densidade tem relação com o teor de umidade, ou seja, quanto maior a densidade, maior o teor de EPS e também maior umidade, no entanto, novamente o painel com 50\% de EPS fugiu a essa regra. Já os painéis dissolvidos em gasolina e água apresentaram teores de umidade praticamente homogêneos, provavelmente pela adição de água no processo de manufatura.

Verifica-se que tanto a absorção de água em 2 horas como em 24 horas possuem o mesmo desempenho, independentemente de como o EPS tenha sido dissolvido, pois quanto menor a quantidade de madeira, menor também é a absorção de água dos painéis. Confrontando-se as análises de densidade, teor de umidade e absorção, quanto maior a densidade, maior o teor de umidade, sendo também menor a absorção de água dos painéis. A relação entre densidade e absorção pode ser compreendida pela consequente diminuição dos vazios com o aumento da densidade, resultando uma menor absorção.

A norma brasileira NBR 14.810 da ABNT (2006) não limita os valores de absorção, entretanto os melhores resultados foram apresentados pelos painéis com 50\% EPS e 50\% serragem. Observa-se que quanto menor a quantidade de madeira e maior a de EPS, melhor será o comportamento dos painéis, pois haverá menor absorção de água, mesmo que haja uma quantidade excessiva de umidade.

Quanto ao inchamento em espessura, observa-se que nas análises em 2 horas, à exceção do painel $30 \%$ EPS e $70 \%$ serragem, dissolvido em gasolina, os demais forneceram valores dentro dos padrões exigidos na norma brasileira NBR 14.810 da ABNT (2006), que é de 8\%, mesmo havendo grande absorção de água, avaliados nos ensaios anteriores. Nota-se que quanto menor a quantidade de serragem, menor também seu inchamento, apesar de os painéis com 20\% de EPS e $80 \%$ de serragem não acompanharem essa tendência.

Após 24 horas, entretanto, não há como analisá-los de maneira homogênea, pois não há parâmetros de comparações, provavelmente por causa da irregularidade causada pelos vazios internos existentes nos painéis e principalmente pelos erros de leitura verificados após análise (em alguns casos, inchamento em 2 horas maior que em 24 horas, o que é absurdo).

De modo geral, os painéis comportaram-se adequadamente para quase todos os parâmetros avaliados, entretanto, pela análise geral, há uma tendência para a escolha dos painéis produzidos com 
$40 \%$ EPS e $60 \%$ serragem, ou 50\% EPS e 50\% serragem, tantos os produzidos com gasolina como os com gasolina e água, pelos melhores resultados fornecidos.

Antes de serem avaliados os resultados físicos dos painéis, havia sido observado que alguns corpos de prova não apresentavam boa compactação, mas os ensaios físicos foram realizados de maneira satisfatória. Contudo, para os ensaios mecânicos, notou-se que não havia como realizá-los, pela presença de muitos vazios e pouca homogeneidade encontrada nos painéis com $20 \%$ de EPS e $80 \%$ de serragem, como também nos de $30 \%$ EPS e $70 \%$ de serragem, tantos os dissolvidos com gasolina como os dissolvidos com gasolina e água. Da mesma maneira, alguns corpos de prova, como, por exemplo, os de tração paralela, não puderam nem mesmo ser confeccionados, pois o painel acabou fragmentando e não fornecendo material suficiente para essa operação.

Assim, apenas foram ensaiados os painéis com $40 \%$ EPS e $60 \%$ serragem, bem como os de $50 \%$ EPS e 50\% serragem, dissolvidos com gasolina, e gasolina e água. Nota-se que eles foram os mesmos que forneceram os melhores resultados nos ensaios físicos. Os resultados dos ensaios mecânicos iniciais, obtidos nas diferentes porcentagens EPS/serragem, encontram-se resumidos na tabela 3.

Tabela 3. Resultados das análises mecânicas iniciais.

Table 3. Results of initial mechanical analysis.

\begin{tabular}{lccccccc}
\hline $\begin{array}{l}\text { Proporção } \\
\text { EPS/ } \\
\text { serragem (\%) }\end{array}$ & $\begin{array}{c}\text { Solvente } \\
\text { usado }\end{array}$ & $\begin{array}{c}\text { Cisalhamento } \\
\text { (MPa) }\end{array}$ & $\begin{array}{c}\text { Tração } \\
\text { paralela } \\
(\mathbf{M P a})\end{array}$ & $\begin{array}{c}\text { Compressão } \\
\text { longitudinal } \\
(\mathbf{M P a})\end{array}$ & $\begin{array}{c}\text { Ligação } \\
\text { interna } \\
(\mathbf{M P a})\end{array}$ & $\begin{array}{c}\text { MOR } \\
(\mathbf{M P a})\end{array}$ & $\begin{array}{c}\text { MOE } \\
(\mathbf{M P a})\end{array}$ \\
\hline $40 / 60$ & Gasolina/água & 3,64 & 1,20 & 5,11 & 0,49 & 2,09 & 99,37 \\
$50 / 50$ & Gasolina/água & 4,45 & 2,90 & 6,08 & 0,24 & 4,79 & 513,99 \\
$40 / 60$ & Gasolina & 2,37 & 7,36 & 3,29 & 0,13 & 2,11 & 266,97 \\
$50 / 50$ & Gasolina & 2,48 & 1,37 & 3,54 & 0,31 & 2,81 & 400,04 \\
\hline
\end{tabular}

Pela análise dos resultados nos ensaios mecânicos, observa-se que os valores de cisalhamento relacionam-se com a proporção de EPS existente no painel, pois, de modo geral, quanto maior a quantidade de adesivo, melhor o comportamento quanto ao cisalhamento. Como não existem dados para os padrões exigidos, uma vez que esse ensaio não é citado pelas normas de aglomerados, não há como saber se apresentam resultados satisfatórios, entretanto, os máximos valores obtidos giram em torno de $80 \%$ da resistência média das madeiras da classe de resistência C 20 definida pela norma NBR 7190, da ABNT (1997).

Ao observar os dados quanto ao ensaio de tração paralela, percebe-se um resultado exagerado, provavelmente de erro na condução do ensaio, para o painel 40\% de EPS e 60\% serragem, dissolvidos em gasolina. Para os demais painéis, embora a norma brasileira não defina limites para esses resultados, os dados observados não atendem ao limite mínimo de 4 a 5,5 MPa, estabelecido na norma americana ASTM 1037 (1996), utilizada por Nascimento (2003) para comparação. Excluído o resultado não esperado, o mesmo comportamento observado no cisalhamento fica explicitado para tração paralela às faces, ou seja, quanto maior a quantidade de EPS, maior os valores de cisalhamento e consequentemente maior tração, estando relacionados também aos valores dos resultados físicos de densidade.

Quanto às análises dos ensaios de compressão, apesar de não haver normas para sua avaliação, nota-se que quanto menos serragem utilizada (consequentemente mais EPS), o desempenho é melhor. Observa-se também que os painéis produzidos com adição de água fornecem melhores resultados, permitindo ligar o comportamento de compressão longitudinal aos ensaios de cisalhamento, nos quais o comportamento é bem semelhante.

Os resultados de tração perpendicular, também chamada ligação interna, são de extrema importância, uma vez que medem o grau de adesão da chapa e estão diretamente relacionados à quantidade de adesivo utilizado na manufatura (PEDRAZZI et al., 2006). Também podem estar relacionados à densidade, tempo e temperatura de prensagem. Para esses resultados, apenas o painel com $60 \%$ serragem e $40 \%$ EPS, dissolvido em gasolina, apresentou-se fora dos padrões expostos, pois a norma brasileira NBR 14.810 da ABNT (2006) limita entre 0,20 MPa a 0,40 MPa o valor mínimo aceitável para tração perpendicular, dependendo da espessura do painel. Por medir o grau de adesão das partículas, notase que o EPS como adesivo mostrou-se promissor.

Os dados obtidos para o módulo de ruptura (MOR) estão muito abaixo dos padrões exigidos na norma brasileira NBR 14.810 da ABNT (2006), que, para chapas com espessura entre 14 e $20 \mathrm{~mm}$, é de $16 \mathrm{MPa}$. No entanto, nota-se que quanto menor a quantidade de serragem, maior essa resistência. Os 
painéis de 50\% EPS e 50\% serragem dissolvidos com gasolina e água forneceram os melhores resultados. A baixa resistência do EPS à flexão, de $0,15 \mathrm{MPa}$ a 0,24 MPa (ABRAPEX, 2010), e a relativamente baixa homogeneidade dos painéis (manufatura artesanal), provavelmente são os responsáveis pelos baixos valores de MOR encontrados nos painéis, pois a ruptura por tração está intimamente ligada à quantidade de adesivo e a defeitos localizados.

Apesar da NBR 14.810 da ABNT (2006) não apresentar limites para o módulo de elasticidade, alguns pesquisadores, como Azambuja et al. (2006) e Battistelle et al. (2008), o comparam com os valores estabelecidos pela norma CS 236-66 (COMMERCIAL STANDART, 1968), que o limita ao mínimo de $24500 \mathrm{kgf} / \mathrm{cm}^{2}$ (2450 MPa). Também quanto ao módulo de elasticidade, os valores foram muito inferiores aos exigidos nessa norma, mas mostra-se com melhor valor o painel $50 \%$ serragem e $50 \%$ EPS, dissolvidos com gasolina e água. Todos os painéis apresentaram valores muito inferiores à norma, uma vez que os plásticos, em geral, têm baixa rigidez (BAUER, 2004), e o EPS, usado como adesivo, é um plástico.

É interessante observar que, quanto à flexão estática, todos os resultados foram muito baixos, provavelmente pelo emprego do adesivo EPS, que possui baixa resistência mecânica.

Avaliados todos os resultados físicos e mecânicos, verificou-se que o painel 50\% EPS e 50\% serragem, produzido com gasolina e água, foi o que obteve os melhores desempenhos. Assim, foram produzidos 10 desses painéis, dos quais foram retirados todos os corpos de prova para a realização dos ensaios de caracterização física e mecânica.

\section{Placas selecionadas}

Ensaios físicos

Os resultados dos ensaios físicos encontram-se na tabela 4.

Tabela 4. Resultados dos ensaios físicos.

Table 4. Results of physical tests.

\begin{tabular}{lcccccc}
\hline $\begin{array}{l}\text { Corpo de } \\
\text { prova }\end{array}$ & $\begin{array}{c}\text { Densidade } \\
\left(\mathbf{k g} / \mathbf{m}^{\mathbf{3}}\right)\end{array}$ & $\begin{array}{c}\text { Teor de } \\
\text { umidade } \mathbf{( \% )}\end{array}$ & $\begin{array}{c}\text { Absorção } \\
\mathbf{2 h}(\mathbf{\%})\end{array}$ & $\begin{array}{c}\text { Absorção } \\
\mathbf{2 4 h} \mathbf{( \% )}\end{array}$ & $\begin{array}{c}\text { Inchamento } \\
\mathbf{2 h}(\boldsymbol{\%})\end{array}$ & $\begin{array}{c}\text { Inchamento } \\
\mathbf{2 4 h}(\boldsymbol{\%})\end{array}$ \\
\hline 01 & 604 & 9,0 & 3,56 & 45,48 & 3,3 & 4,47 \\
02 & 642 & 9,0 & 6,45 & 40,89 & 2,6 & 2,84 \\
03 & 580 & 8,9 & 3,83 & 43,44 & 1,0 & 2,36 \\
04 & 595 & 9,5 & 5,73 & 24,24 & 1,6 & 2,45 \\
05 & 595 & 9,0 & 5,91 & 36,31 & 4,3 & 4,04 \\
06 & 612 & 9,0 & 4,58 & 21,86 & 1,2 & 2,34 \\
07 & 609 & 9,0 & 5,69 & 28,19 & 2,0 & 2,76 \\
08 & 614 & 9,4 & 4,92 & 30,27 & 1,3 & 2,94 \\
09 & 547 & 9,5 & 6,03 & 19,67 & 3,2 & 3,39 \\
10 & 623 & 9,0 & 4,35 & 23,18 & 2,9 & 3,73 \\
\hline Média & 602 & 9,1 & 17,38 & 31,35 & 2,34 & 3,13 \\
Desvio-padrão & 25,79 & 0,24 & 6,32 & 9,52 & 1,09 & 0,74 \\
Coef. variação & 0,04 & 0,03 & 0,36 & 0,30 & 0,47 & 0,24 \\
t (9,95\%) & 2,262 & 2,262 & 2,262 & 2,262 & 2,262 & 2,262 \\
Lim. Inf. (\%) & 584 & 8,96 & 12,85 & 24,54 & 1,56 & 2,60 \\
Lim. Sup. (\%) & 621 & 9,30 & 21,90 & 38,17 & 3,12 & 3,66 \\
\hline
\end{tabular}

\section{Densidade}

Observando-se a tabela 4 , nota-se, pelo coeficiente de variação da densidade $(\delta \cong 4 \%)$, que os painéis apresentam-se bastante homogêneos. Para madeiras maciças, o coeficiente de variação médio, segundo Almeida (2008), que analisou os resultados dos ensaios de densidades realizados pelo Grupo de Pesquisas em Madeiras e Estruturas de Madeira (GPMEM), gira em torno de 6,19\%, sendo o percentil de $95 \%$ de $10,5 \%$.

A baixa variabilidade encontrada pode ser explicada pelo fato de todos os painéis seguirem o mesmo processo de manufatura, idêntica pressão e igual tempo de prensagem. A densidade média de 602 $\mathrm{kg} / \mathrm{m}^{3}$ das chapas propostas neste trabalho as classifica como de média densidade e está em acordo com os parâmetros definidos na norma brasileira NBR 14.810, da ABNT (2006). 


\section{Teor de umidade}

Os resultados, apresentados na tabela 4 indicam que todos os painéis atendem à norma brasileira NBR 14.810 da ABNT (2006), que limita a umidade entre 5\% e 11\%, já que a média obtida foi de 9,1\%.

O coeficiente de variação $(\delta \cong 3 \%)$ indica teor de umidade bastante homogêneo entre os painéis fabricados. Para madeiras maciças, segundo Dias (2005), ao comentar estudos de Lahr (1990) e Salles (1996), o coeficiente de variação gira em torno de $18 \%$.

\section{Absorção de água e inchamento em espessura}

Não há exigências, em norma, quanto aos valores estipulados para absorção de água em 2 ou 24 horas. No entanto, Nascimento (2003) informa valores médios para chapas industrializadas de pínus entre 12 e $27 \%$, e de eucalipto entre 16 e $50 \%$, para absorção em 2 e 24 horas, respectivamente.

Neste trabalho, o valor médio encontrado em 2 horas apresenta-se um pouco acima dos citados, sendo de $17,38 \%$. Já para a absorção em 24 horas, o valor está abaixo dos comerciais em eucalipto e próximo aos de pínus, com $31,35 \%$.

$\mathrm{Na}$ tabela 4 , observam-se elevados coeficientes de variação $\left(\delta_{2 \mathrm{~h}} \cong 47 \%\right.$ e $\left.\delta_{24 \mathrm{~h}} \cong 24 \%\right)$ para os inchamentos, indicando grande variabilidade desses valores. Ainda assim, os resultados de inchamento estão bem abaixo dos padrões exigidos na norma brasileira NBR 14.810, da ABNT (2006), sendo de 8\% para 2 horas, que não foram ultrapassados nem após 24 horas.

Comparando-se inchamento em espessura com absorção de água, ressalte-se que, apesar de haver uma quantidade grande de absorção de água, o painel não incha. Por haver vazios no interior do corpo de prova, ele é preenchido com a água, que não é absorvida pelas partículas, nem tampouco pelo adesivo, já que este é provavelmente o responsável por tal ocorrência. Assim, recomenda-se a utilização de um material para preenchimento dos vazios presentes no produto final, pois há nítida percepção de que a água se acumula nos vazios existentes no material, mesmo não havendo o inchamento da placa. A utilização de emulsão de parafina, por exemplo, poderia ser uma alternativa para se reduzir a absorção de água. Outra opção para a diminuição dos vazios existentes no interior da placa é a utilização da préprensagem com carga mais elevada, ocorrendo maior consolidação do colchão, antes da prensagem. Por fim, a classificação granulométrica da serragem residuária, por influenciar nas propriedades finais.

Ensaios mecânicos

Os resultados dos ensaios mecânicos encontram-se na tabela 5.

Tabela 5. Resultados dos ensaios mecânicos.

Table 5. Results of mechanical tests.

\begin{tabular}{|c|c|c|c|c|c|c|}
\hline \multirow{2}{*}{$\begin{array}{l}\text { Corpo de } \\
\text { prova }\end{array}$} & \multirow{2}{*}{$\begin{array}{c}\text { Resistência ao } \\
\text { cisalhamento } \\
\text { (MPa) }\end{array}$} & \multirow{2}{*}{$\begin{array}{l}\text { Resistência à } \\
\text { tração paralela } \\
\text { (MPa) }\end{array}$} & \multirow{2}{*}{$\begin{array}{l}\text { Resistência à } \\
\text { compressão } \\
\text { (MPa) }\end{array}$} & \multirow{2}{*}{$\begin{array}{l}\text { Resistência à } \\
\text { tração } \\
\text { perpendicular } \\
(\mathrm{MPa})\end{array}$} & \multicolumn{2}{|c|}{$\begin{array}{c}\text { Resistência à flexão } \\
\text { estática }\end{array}$} \\
\hline & & & & & $\begin{array}{l}\text { MOR } \\
\text { (MPa) }\end{array}$ & $\begin{array}{l}\text { MOE } \\
\text { (MPa) }\end{array}$ \\
\hline 01 & 3,03 & 0,81 & 1,49 & 0,49 & 3,36 & 415,79 \\
\hline 02 & 5,38 & 1,61 & 1,57 & 0,28 & 5,39 & 441,75 \\
\hline 03 & 3,99 & 1,29 & 3,22 & 0,33 & 4,53 & 404,81 \\
\hline 04 & 3,82 & 1,69 & 1,17 & 0,44 & 3,94 & 337,80 \\
\hline 05 & 4,36 & 0,95 & 1,88 & 0,27 & 5,09 & 401,83 \\
\hline 06 & 4,54 & 1,41 & 1,79 & 0,71 & 4,96 & 365,00 \\
\hline 07 & 4,92 & 0,74 & 1,84 & 0,30 & 4,73 & 475,76 \\
\hline 08 & 3,78 & 2,43 & 3,82 & 0,67 & 4,48 & 377,15 \\
\hline 09 & 2,86 & 0,39 & 1,46 & 0,34 & 4,96 & 472,64 \\
\hline 10 & 2,93 & 0,82 & 2,12 & 0,33 & 3,75 & 479,88 \\
\hline Média & 3,96 & 1,21 & 2,04 & 0,42 & 4,52 & 417,24 \\
\hline Desvio-padrão & 0,86 & 0,60 & 0,84 & 0,16 & 0,65 & 49,51 \\
\hline Coef. variação & 0,22 & 0,49 & 0,41 & 0,38 & 0,14 & 0,12 \\
\hline $\mathrm{t}(9,95 \%)$ & 2,262 & 2,262 & 2,262 & 2,262 & 2,262 & 2,262 \\
\hline Lim. Inf. (\%) & 3,35 & 0,79 & 1,44 & 0,30 & 4,05 & 381,83 \\
\hline Lim. Sup. (\%) & 4,57 & 1,64 & 2,64 & 0,53 & 4,98 & 452,65 \\
\hline
\end{tabular}

Cisalhamento 
Os corpos de prova e os respectivos ensaios foram adaptados aos dos métodos definidos na NBR 7190 - Projeto de estruturas de madeira, da ABNT (1997).

Os resultados forneceram uma média de $3,96 \mathrm{MPa}$, com coeficiente de variação de $22 \%$. Por falta de parâmetros, os dados foram apenas citados, sem qualquer análise de comparação.

\section{Tração paralela às faces}

Embora a norma brasileira NBR 14.810 da ABNT (2006) não estabeleça limite para a resistência à tração paralela às faces, os resultados obtidos, de média 1,21 MPa, estão muito abaixo dos obtidos por Nascimento (2003), que estudou aglomerados e comparou resultados com a norma americana "ASTM 1037: Tensile Strength Parallel to Surface" (Resistência à tração paralela à superfície), da ASTM (1996), que recomenda aos fabricantes tensões entre 40 e $55 \mathrm{daN} / \mathrm{cm}^{2}$, ou seja, 4 e 5,5 MPa. Provavelmente os baixos valores obtidos no presente trabalho se devem à baixa resistência mecânica do EPS, usado como adesivo.

Outro fator importante a ser citado refere-se ao elevado coeficiente de variação observado (49\%), indicando grande heterogeneidade nos resultados. Provavelmente duas são as razões para esse fato: 1) falta de homogeneidade na mistura de cada placa, tendo em vista terem sido artesanalmente produzidas, uma vez que a resistência à tração está intimamente associada a defeitos localizados no interior da placa; e 2) deficiências do ensaio de tração, que podem introduzir esforços secundários de torção ou de flexão, devido a falhas de produção do corpo de prova ou de seu posicionamento na máquina de ensaios.

\section{Compressão longitudinal}

Como a NBR 14.810 da ABNT (2006) não estabelece valores de tolerância para a resistência à compressão longitudinal, os resultados obtidos servem para análise isolada, sem padrão de comparação.

Observa-se uma resistência média de compressão normal de 2,04 MPa e um coeficiente de variação de $41 \%$. O valor relativamente alto no coeficiente de variação pode ser atribuído à heterogeneidade da mistura na confecção artesanal das placas.

\section{Tração perpendicular (ligação interna)}

De acordo com a NBR 14.810 da ABNT (2006), os valores para tração perpendicular variam de $0,20 \mathrm{MPa}$ a 0,40 MPa, dependendo da espessura do painel. Chapas com espessura entre 5 e $13 \mathrm{~mm}$, como também entre 14 e $20 \mathrm{~mm}$, devem apresentar valores mínimos de 0,40 MPa e 0,35 MPa, respectivamente. A maioria dos corpos de prova ensaiados, como também sua média final, alcançaram valores acima dos citados. Entretanto, observa-se que a variabilidade dos resultados, indicada pelo coeficiente de variação, apresentou-se elevada (38\%), possivelmente devido à heterogeneidade na produção artesanal das placas. Assim, pode-se afirmar que a resistência à tração perpendicular foi compatível aos valores recomendados pela norma brasileira.

\section{MOR}

A norma brasileira NBR 14.810 da ABNT (2006) limita o valor de MOR, na flexão estática, em $16 \mathrm{MPa}$ para chapas com espessuras entre 14 e $20 \mathrm{~mm}$. Nos resultados da tabela 5, apesar do baixo coeficiente de variação (14\%), que indica homogeneidade de resultados, os valores de MOR estão muito abaixo dos exigidos, apresentando média de 4,52 $\mathrm{MPa}$, devido à baixa resistência do EPS usado como adesivo.

\section{MOE}

A norma brasileira NBR 14.810 da ABNT (2006) não estabelece limite mínimo de MOE na flexão estática. Por outro lado, Nascimento (2003) e Dias (2005) compararam seus resultados à norma comercial CS 236-66, que limita MOE em $2450 \mathrm{MPa}$ para os aglomerados com densidade de 0,60 e $0,80 \mathrm{~g} / \mathrm{cm}^{3}$.

Os valores obtidos para MOE, neste trabalho, apresentaram-se bem inferiores aos exigidos na norma americana. Isso pode ser explicado pelo fato de o adesivo utilizado possuir baixa resistência ao módulo de elasticidade, transferindo, dessa maneira, as propriedades para a chapa. Assim, torna-se 
imprescindível a adição de substâncias que aumentem sua resistência final, agregando maiores características às chapas.

\section{CONCLUSÕES E RECOMENDAÇÕES}

- Como conclusões do trabalho realizado, pode-se afirmar que é possível produzir painéis aglomerados utilizando serragem, com múltiplas espécies como partículas, e EPS dissolvido em gasolina como adesivo. Para melhorar a viscosidade da mistura pode-se adicionar água.

- O painel que apresentou melhor comportamento entre os avaliados foi montado com $50 \%$ de serragem e 50\% de EPS dissolvido em $2000 \mathrm{ml}$ de gasolina, com adição de $250 \mathrm{ml}$ de água.

- A caracterização física desse painel mostrou-se compatível aos padrões recomendados pela norma brasileira para o comércio. Os valores muito baixos de inchamento em espessura tornam esses painéis de uso promissor para áreas externas, embora tenham apresentado elevados valores de absorção.

- A caracterização mecânica dos painéis indicou ligação interna (tração perpendicular) compatível com as recomendações das normas brasileiras. Para compressão longitudinal e cisalhamento, foram obtidos resultados adequados. Já para flexão estática (MOR e MOE) e para tração paralela às faces, os resultados foram baixos, provavelmente devido à baixa resistência do adesivo utilizado (EPS).

- Quanto à utilização dos painéis aglomerados de serragem e EPS, entende-se como possível sua produção e utilização em tapumes, porta de móveis, forros de habitações, com indicação até para áreas molhadas, laterais de móveis não submetidos a esforços, divisórias internas de edificações e móveis para banheiro que entram em contato direto com a umidade. De modo geral, podem ser indicados ao uso interno e externo, desde que não sejam mecanicamente solicitados. Outra utilização possível refere-se ao setor de embalagens e objetos decorativos, assim como podem ser usados para isolamento térmico e acústico, necessitando de maiores estudos e ensaios.

- Quanto ao solvente do adesivo, adverte-se que o EPS é dissolvido por poucos tipos de líquidos, por consequência de sua composição. Os citados na bibliografia são os solventes orgânicos derivados do petróleo, como óleos, gasolina e diesel. Outra opção encontrada é a acetona, que também é inflamável. O emprego desses solventes pode elevar os níveis dos riscos envolvidos no processo de produção e de utilização, sendo recomendável o emprego de aditivos retardantes de fogo, incorporados ao processo de produção ou impregnados nos painéis após a prensagem.

- Quanto aos vazios existentes, deve-se ressaltar que os valores de absorção foram elevados, embora os de inchamento muito menores do que o exigido na norma brasileira, revelando boa estabilidade dimensional.

- É interessante apontar que, como a ligação interna apresentou resultados satisfatórios, o adesivo mostrou-se propício. Assim, pode-se manter o EPS como adesivo e melhorar o desempenho mecânico com o aumento da densidade dos painéis pela simples adição de maior pressão durante a manufatura dos painéis.

\section{REFERÊNCIAS}

ALMEIDA, G. A. Sobre o valor característico da densidade aparente da madeira. Cuiabá: UFMT, Trabalho de Conclusão de Curso (Graduação) - Universidade Federal de Mato Grosso, 2008.

ASSIS, R. Adesivos poliuretanos derivados de PET reciclado: síntese, caracterização e aplicação. Campinas: UNICAMP, Dissertação (Mestrado) - Instituto de Química, Universidade Estadual de Campinas, 2004.

ASSOCIAÇÃO BRASILEIRA DE NORMAS TÉCNICAS (ABNT). NBR 14810 - Chapas de madeira aglomerada. ABNT. Rio de Janeiro, 2006.

ASSOCIAÇÃO BRASILEIRA DE NORMAS TÉCNICAS (ABNT). NBR 7190 - Projeto de Estruturas de Madeira. ABNT: Rio de Janeiro. 1997. 
ASSOCIAÇÃO BRASILEIRA DO POLIESTIRENO EXPANDIDO (ABRAPEX). Disponível em <http://www.abrapex.com.br>. Acesso em: 05/2010.

ASSOCIAÇÃO INDUSTRIAL DO POLIESTIRENO EXPANDIDO (ACEPE). Disponível em: <http://www.acepe.pt>. Acesso em: 05/2010.

AZAMBUJA, A. Estudo experimental de adesivos para fabricação de madeira laminada colada: avaliação da resistência de emendas dentadas, da durabilidade e de vigas. São Carlos: USP, 2006. Tese (Doutorado) - Escola de Engenharia de São Carlos, Ciência e Engenharia de Materiais, Universidade de São Paulo, 2006.

BATTISTElle, R. A. G.; MARCÍLIO, C.; LAHR, F. A. R. Emprego do bagaço da cana-de-açúcar (Saccharum officinarum) e das folhas caulinares do bambu da espécie Dendrocalamus giganteus na produção de chapas de partículas. Revista Minerva - Pesquisa \& Tecnologia, São Carlos, v. 5, n. 3, p. $297-305,2008$.

BAUER, L. A. F. Materiais de construção. v. 2, 5. ed. Uberlândia: LTC, 2004.

DIAS, F. M. Aplicação de resina poliuretana à base de mamona na fabricação de painéis de madeira compensada e aglomerada. São Carlos: USP, 2005. Tese (Doutorado) - Escola de Engenharia de São Carlos, Universidade de São Paulo, 2005.

DONATI, R. D. Produção de painéis reconstituídos no Brasil - passado, presente e futuro. Disponível em: ,<ttp://www.abipa.org.br/entrevistaRosane.php>. Acesso em: 09/2010.

IWAKIRI, S. Painéis de madeira reconstituída. Curitiba: FUPEF, 2005.

LAHR, F. R. A. Considerações a respeito da variabilidade de propriedades de resistência e elasticidade da madeira. São Carlos, 1990. Tese (Livre Docência) - Escola de Engenharia de São Carlos, Universidade de São Paulo, 1990.

MATtOS, R. L.; GONÇALVES, R. M.; CHAGAS, F. B. Painéis de madeira no Brasil: panorama e perspectivas. BNDS Setorial, Rio de Janeiro, v. 27, p. 121 - 156, 2008.

NASCIMENTO, M. F. CHP: chapas de partículas homogêneas - madeiras do nordeste do Brasil. São Carlos: USP, 2003. Tese (Doutorado) - Escola de Engenharia de São Carlos, Universidade de São Paulo, 2003.

PEDRAZZI, C.; HASELEIN, C. R.; SANTINI, E. J.; SCHNEIDER, P. R. Qualidade de chapas de partículas de madeira aglomerada fabricadas com resíduos de uma indústria de celulose. Ciência Florestal, Santa Maria, v. 16, n. 2, p. 201 - 212, 2006.

SALLES, A. Proposição de classes de resistência para madeira. São Calos, 1993. Tese (Doutorado) Escola de Engenharia de São Carlos, Universidade de São Paulo, 1993. 